\begin{tabular}{|c|c|}
\hline sin scientifitcoma & $\begin{array}{l}\text { International Journal of Trend in Scientific } \\
\text { Research and Development (IJTSRD) }\end{array}$ \\
\hline 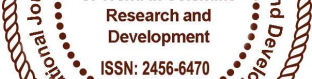 & International Open Access Journal \\
\hline 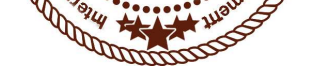 & ISSN No: 2456 - 6470 | www.ijtsrd.com | Volume - 1 | Issue - 5 \\
\hline
\end{tabular}

\title{
Control Strategies of Frequency Regulation in Wind Based Power System: A Review
}

\author{
Faisal Raina \\ M.Tech Scholar, Electrical Engineering \\ Department, YIET, Gadhauli, Yamunanagar, \\ Haryana
}

\author{
Gagan Deep Yadav \\ A.P., Electrical Engineering Department, YIET, \\ Gadhauli, Yamunanagar, Haryana
}

\begin{abstract}
The increasing wind penetration in today's power grids has led to growing interest in the frequency control capabilities of wind generation. Several publications have proposed a variety of methods both on the levels of a single turbine and of a wind farm. This paper focuses on the role of wind generation in a system's primary frequency control. Wind turbine control methods that enable frequency support and control are presented. The advantages and disadvantages of each method are discussed.
\end{abstract}

Keywords: Ancillary services, Frequency response, Emulating inertia, Primary frequency control, Wind turbines

\section{INTRODUCTION}

In recent years, there have been problems such as exhaustion of fossil fuel, e.g., coal and oil, and environmental pollution. In order to overcome these problems, renewable energy sources (RES) can be installed for the reduction of greenhouse gases as well as granting significant side benefits and contributing to economic growth.

Among available RES technologies, wind power is expected to contribute the largest portion. During the last decades, Many large wind farms have already been installed so far and recently huge offshore wind farms have also been integrated in the power networks. But with the ever increasing development of wind power, the impacts on grid frequency and operation of the power system become more significant. First of all, as the wind penetration in a system increases, the randomness and fluctuation of wind power increase. The frequency variation of power system due to wind generator output fluctuations increases. Frequency variations will change the operation point of wind turbines due to the change of value of the machine reactance and the slip. Generally, wind parks are equipped with a frequency relay that disconnects the wind park after a frequency disturbance. When the wind power penetration of a grid is high, a massive wind farms disconnection can lead to power system oscillations [1].

Secondly, modern wind farms are mostly equipped with Variable Speed Wind Turbines (VSWT), variable speed turbine technologies use back-to-back power electronic converters for the grid connection. The intermediate DC voltage bus creates an electrical decoupling between the machine and the grid. Therefore variations in grid frequency are not seen by the generator rotor, the power system apparent inertia decreases as the wind penetration in a system increases. Consequently greater rates of frequency change will be observed in various system contingencies (e.g. generating unit loss) or sudden load variations. This implies that the spinning reserve will have less time to react to the power imbalance, probably resulting in larger frequency deviations. This effect is mainly noticeable in frequency deviations occurring in small or isolated systems with an important penetration of wind power [2]. Additionally the increase in the rate of frequency change will lead to additional regulation burden on conventional units. And there is also the more common case where, due 
to power system stability issues, wind generation is partially curtailed.

Thirdly, Due to the uncertain characteristics of the wind production, the general way of the reserve management for wind integration is to provide additional reserve margin by conventional plants. Such a strategy could not only increase the operating cost but also impose additional unit stress during the frequency event. If wind generation is displacing thermal plant then the sources of reserve available to the system will decline and fewer conventional units will be available to share the operating reserve burden. Therefore, as the wind penetration in a system increases, reserve management by the conventional plants, that is, hydraulic and thermal power stations, will be difficult in the near future, especially in an isolated power system like a small island which has weak capability of power regulation.

In order to achieve a more secure operation, reduce the impact of the wind penetration, wind Turbine generation (WTG) should be more grid-friendly, WTG has to contribute with services that are normally delivered by conventional power plants. Sooner or later, the large wind farms will have to behave as active controllable components in the power system [3]. This means that wind farms will be able to share some of the duties carried out today by the conventional power plants, such as regulating active and reactive power and performing frequency and voltage control on the grid. Therefore, the need to study the way in which wind units could participate in system frequency support strongly arises.

This paper focuses on the participation of a wind turbine to the primary frequency control. Wind turbine control methods that enable frequency support and control are presented. The advantages and disadvantages of each method are discussed. The possibility of using variable speed wind turbine to provide primary power reserve is investigated. The capacity of a variable speed wind generator to maintain a primary power reserve without direct wind speed measurement nor additional storage system is discussed.

\section{National grid codes about frequency and active power requirements for wind farms}

In recent years, the various national Grid Codes have imposed some frequency and active power requirements on wind farms. For example The Great Britain (GB) Grid Code states that wind farms must provide balancing services that are originally supported from conventional plants, all wind farms must be capable of meeting the frequency response requirements of primary, secondary and highfrequency response [3]. When the frequency drops, say a frequency deviation of $0.5 \mathrm{~Hz}$, the generator output power should increase by an amount equal to primary response, within the time period $0-10 \mathrm{~s}$ and be sustained for a further $20 \mathrm{~s}$. The generators should maintain power output at the secondary response from $30 \mathrm{~s}$ to $30 \mathrm{~min}$ in order to stabilize the frequency. In the event of a frequency increase, the generator output power should decrease by an amount equal to highfrequency response within the time period 0-10 s.

Hydro-Quebec grid code states that wind farms with rated power greater than $10 \mathrm{MW}$ must have frequency control system that helps to reduce large $(>0.5 \mathrm{~Hz})$ and short-term $(<10 \mathrm{~s})$ frequency deviations in power systems [4].

According to the Danish Grid Code [5], it is required to control the output power of individual wind generators using an automatic frequency regulation controller. The transmission system operator (TSO) may demand primary response from 47 to $50 \mathrm{~Hz}$ and high-frequency response from 50 to $53 \mathrm{~Hz}$ with a headband of 49.9-50.1 Hz.

The German Grid Code [6] requires wind farms to reduce their available power production when the network frequency is higher than normal values. Generating plant with a rated capacity less than 100 MW can provide primary response by an agreement with the transmission system operator (TSO). The Grid Code states that given a frequency deviation of $+0.2 \mathrm{~Hz}$, the primary response of the generating plant should be able to change by $+2 \%$ of the rated power output evenly in $30 \mathrm{~s}$ and be maintained for at least 15 $\mathrm{min}$. If the frequency rises to a value more than 50.5 $\mathrm{Hz}$, the TSO can demand a reduction of the active power.

In Spain, there are plans to implement in a new operative procedure strengthen requirements for the power and frequency control contribution from wind generators. This includes the participation in the power and frequency control schemes and in addition requirements for inertia provision by emulation from wind energy converters [7].

\section{Comparison of the frequency response of VSWT and conventional plant}

Conventional generating plants use directly connected synchronous generators. This means that there is a 
International Journal of Trend in Scientific Research and Development (IJTSRD) ISSN: 2456-6470

coupling between the power system frequency and the electromagnetic torque (and the resulting electrical active power output) of the generators. When the power system frequency suddenly decreases the electrical active power suddenly - and temporarilyincreases due to this coupling. This is known as the "natural" inertial response of the generator, and it contributes to frequency stabilization.

Classical VSWTs are characterized by lower inertia than classical power plants. Further, some VSWTs technologies use back-to-back power electronic converters for the grid connection. The intermediate DC voltage bus creates an electrical decoupling between the machine and the grid. Therefore although wind turbines also have a significant amount of kinetic energy stored in the rotating mass of their blades Similar to conventional generators. This energy will not contribute to the inertia of the grid as the rotational speed is decoupled from the grid frequency by a power electronic converter. However through the addition of a control loop, variable speed wind turbines can make the "hidden inertia" available to the grid. In this way, variable speed wind turbines may be configured to emulate an inertial response similar to that of synchronous generation.

\section{Method to enable variable speed wind turbine primary regulation}

To solve the problems mentioned above, many experts and scholars have been doing a large amount of research. There are three methods to allows variable speed wind turbine to participate effectively in system frequency regulation, the first is Inertial Control Method, the second is power reserve Control Method, the third is the other method such as communication method etc.

\section{Inertial control}

Recently some literatures proposed methods to meet inertial response of VSWT. Most of these methods introduce a supplementary loop into active power control loop. The loop is activated during frequency deviations. It tries to reduce imbalance between demand and generation by injecting more power from wind turbine to grid until governor increase mechanical power of conventional plant.

Inertial Control may be classified into two categories. Those are, on one hand, control methods that attempt to create an artificial wind turbine inertial response, and on the other hand, control methods that utilize a droop characteristic. The first control strategy has been proposed in [8]. Basically, it gives the wind turbine a response to frequency deviations that is equal to the inherent behavior of a synchronous machine. The additional amount of power supplied is proportional to the derivative of the frequency. (It will be called artificial inertia control). The second control strategy implements on the wind turbine the primary frequency control that is used by conventional power plants. The amount of power supplied is proportional to the difference between the measured and the nominal frequency. It will be called droop control.

In Ref. [9] methods combining the two control strategy to provide inertial response for wind turbines are suggested. Auxiliary control signal proportional to the frequency deviation and frequency deviation derivative are used in order to increase the power of the wind turbine. In Fig. 1, The inertial control loop is responsible for sending additional power regulation signal $\Delta$ Pref to the rotor side converter controller (assuming the converters can provide/withstand the necessary rotor current). When system frequency changes, not only do the synchronous generators respond to this change, the wind plant the inertial control loop also sends additional active power $\Delta$ Pref to the VSWT active power reference Pref. and quickly changes its output active power to share in the frequency restoration process during such short-term frequency fluctuations. Extra power is extracted from kinetic energy stored in rotating turbine. In this way wind turbine operates like a synchronous machine. In other word it can be said that system inertia is increased virtually.

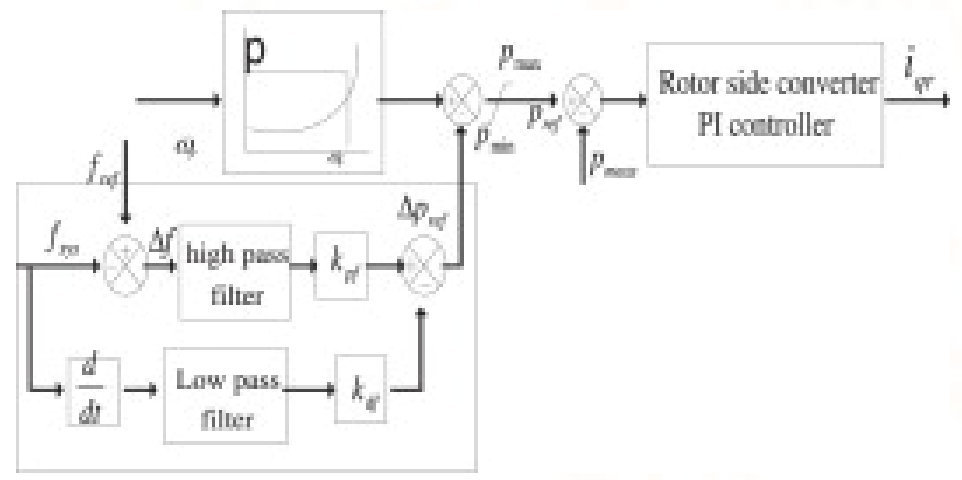

Fig 1. Inertial controller schematic Form power control.

With the given VSWT rotor speed, optimal power signal optimal is obtained and compared with measured output electrical power. The error signal is regulated by the rotor side converter controller to obtain the required rotor current $\mathrm{I}_{\mathrm{qr}}$. 
International Journal of Trend in Scientific Research and Development (IJTSRD) ISSN: 2456-6470

\section{Power reserve control}

Primary regulation is the mechanism implemented by the system to compensate imbalance between demand and generation. A primary regulation consists of a linear variation of generated power with grid frequency. Accordingly, if the grid frequency increases, the generated power should decrease and vice versa. Consequently, in order to be able to implement primary regulation in both directions, a power reserve is needed. For maximization of revenue and resource utilization, Variable speed wind turbines are normally controlled to capture as much power as possible from the wind. Hence they are not available to provide a sustained increase in power output and therefore participate in 'secondary response' services which conventional plants are able to do. The kinetic energy stored in their inertia gives the turbines the possibility to support primary frequency control for a short period. Therefore, In order to perform permanent active power control, it is generally necessary to force the wind turbine to operate in a non-optimal power point, This non-optimal operation of the wind turbine is called de-loaded operation [9].

The ways to de-load wind turbine may be classified into two categories. Those are, on one hand, control methods that attempt to de-load the wind turbine would be to increase the pitch angle and on the other hand, control methods that attempt to de-load the wind turbine is to operate the wind turbine at increased speed. Ideally, both methods would be used simultaneously to optimize the control performance.

Different ways to deload wind turbine are shown on Fig. 3. One method consists in modifying the pitch angle, while keeping the optimal rotation speed corresponding to the actual wind speed (point A on Fig. 2). Another method consists in de-optimizing the rotation speed, either by imposing a lower speed (point B) or a higher speed (as far as the nominal rotation speed is not exceeded) (point C). However, it is necessary to make sure that the rotor speed does not exceed its upper limit [10].

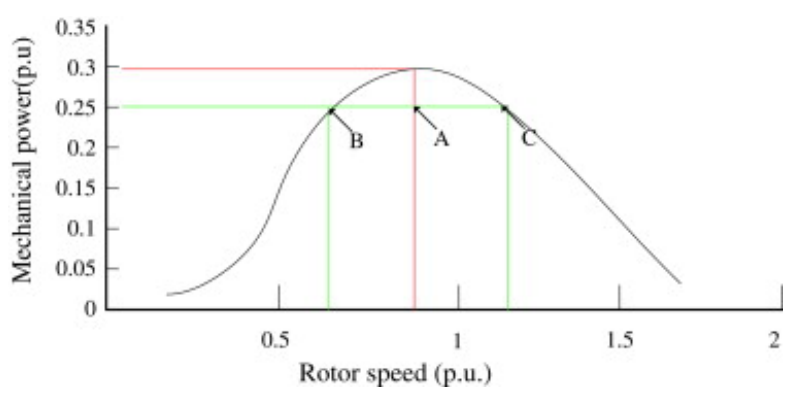

Fig 2. Strategies to release a power margin.
To obtain a power reserve, the WTG must operate at an operating point, which does not extract the maximum power of the wind. For instance, WTG can be required to determine a power reference value sufficiently lower than rated power (balance control) or to limit power production in such a way that a specified power reserve is always available (delta control) etc.

\section{Pitch Control}

Pitch angle control of the wind turbine is designed much like governor control of synchronous machine in this part to make the wind power plant have a longterm frequency regulation capability.

The pitch control limits the active power to a value lower than its nominal value. The resulting active power reserve can be delivered by decreasing the pitch angle as system frequency drops, so that the turbine can extract more mechanical power from wind flow.

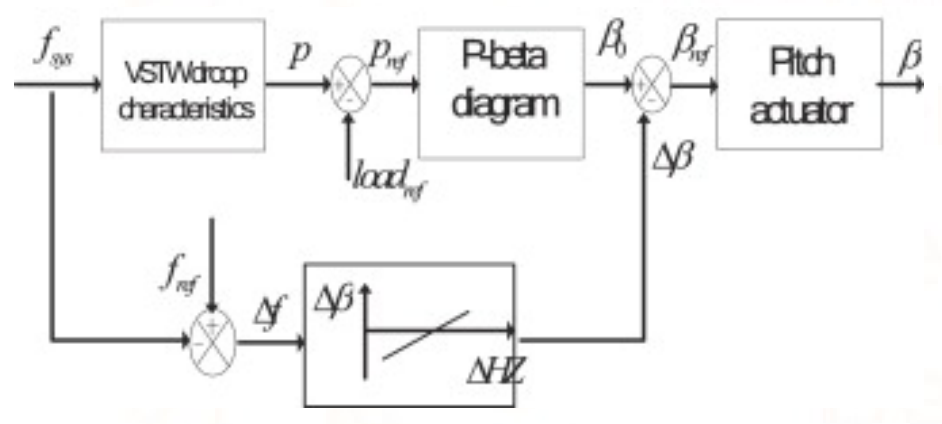

Fig 3. Pitch control schematic

It should be noted that for any given wind speed there is an optimal turbine rotational speed $\omega_{\text {opt }}$ corresponding to the optimal strategy. When deloading through pitching it is desirable to maintain this optimal speed, otherwise the turbine would have to be accelerated (under-speeding case) or decelerated (over-speeding case).

\section{Other methods}

Apart from the methods mentioned above, there are some other methods to enable variable speed wind turbine primary regulation, such as method use communication, and the method that combine wind energy with fuel cells.

Ref. [11] proposed a communication control strategy that Uses output electric power of conventional plant as VSWT reference power, so that VSWT injects an additional power, equal to $\Delta \mathrm{P}$ load just after 
International Journal of Trend in Scientific Research and Development (IJTSRD) ISSN: 2456-6470

imbalanced. Output power is then decrease by suitable time constant.

Ref. [8] Based on a modified inertial control scheme, takes advantage of the fast response capability associated with electronically-controlled VSWT, allowing the kinetic energy stored by rotational masses to be partly and transiently released in order to provide earlier frequency support. An additional improvement is achieved by communicating the VSWT response to conventional generators so that these can eventually take care of the full load imbalance.

Ref. [12] Investigates the possibility for a permanent magnet synchronous generator based VSWT to participate in the primary frequency control without wind speed measurement nor additional storage system. A fuzzy logic supervisory is proposed to obtain a primary reserve whatever the operating points.

In Ref. [13] the authors propose to associate wind generator and fuel cells. In this case the WTG ensures the frequency control during the first instant and the fuel cells take over (the time response of the fuel cells is more important than the WTG). But in this case the fuel cells are only used to participate in the primary frequency control.

\section{Conclusions}

This paper focuses on the participation of a wind turbine to the primary frequency control. In the previous sections various methods to enable frequency control support by wind turbines have been presented, along with the main issues associated with their function and realization. The advantages and disadvantages of each method are discussed. As already mentioned standard methods to enable frequency control by wind turbines do not exist. The authors hope that this paper has contributed towards this direction.

Although there appear to be several alternatives for dealing with the effects of wind generation on frequency regulation, more research is needed to determine what approach will be most effective for specific systems. There may also be a need to rethink secondary control since frequency disturbances due to wind generation tend to fall within the traditional time-scale boundary between primary and secondary control actions.
A method of estimating the reserve from wind turbines, its ratio to conventional generation reserves and its economic issues has not yet been presented in the literature. This is a complex unit commitment problem, one however that will determine the extent to which frequency control by wind generation is economically viable for a power system.

In the literature various methods to establish the concept of kinetic energy discharge for the wind farm to support the system frequency are presented. Further work is required to establish the optimal timing of the kinetic energy discharge and the optimal profile of this power surge in coordination with the characteristics of conventional plants. And verify the existing simulations by laboratory based hardware simulation in future work.

Finally, some other possible applications of such short-term active power supports from a wind farm are also needed to study which could be, for instance, in a small isolated system, in a thermal dominated system and for supporting system islanding operation.

\section{References}

[1] Causebrook A, Atkinson DJ, Jack AG. Fault ridethrough of large wind farms using series dynamic braking resistors (March 2007). IEEE Trans Power Sys 2007;22(3):966e75.

[2] Lalor JRSFDOM and Ritchie G. "Dynamic frequency control with increasing wind generation". In: Proc. IEEE Power Eng. Soc. General Meeting, vol. 2, pp. 1715e1720, Jun. $6 \mathrm{e} 10 ; 2004$.

[3] The grid code. National Grid Company PLC; 2006. 3, Revision 17.

[4] Technical requirements for the connection of generation facilities to the Hydro-Quebec transmission system: supplementary requirements for wind generation, Hydro-Québec, Tech. Rep.; May 2003, revised 2005.

[5] Wind turbines connected to grids with voltages above $100 \mathrm{kVdtechnical}$ regulation for the properties and the regulation of wind turbines, Elkraft System and Eltra Regulation, version TF 3.2.5; Dec 2004.

[6] Grid connection regulations for high and extra high voltage. E.ON Netz GmbH; 2006.

[7] Separata del Borrador del PO. 12.2 Restringida a los Requisitos Técnicos de las Instalaciones Eólicas y Fotovoltaicas; October 2008. 
International Journal of Trend in Scientific Research and Development (IJTSRD) ISSN: 2456-6470

[8] Ekanayake J, Jenkins N. Comparison of the response of doubly fed and fixedspeed induction generator wind turbines to changes in network frequency. IEEE Trans Energy Convers 2004;19(4):800e2.

[9] Mauricio JM, Marano A, Gomez-Exposito A, Martinez Ramos JL. Frequency regulation contribution through variable-speed wind energy conversion systems. IEEE Trans Power Sys 2009;24(1):173e80.

[10] Janssens NA, Lambin, G.; Bragard, N.; Active power control strategies of DFIG wind turbines, Power Tech, 2007 IEEE Lausanne; 2007, 516e521

[11] Akbari M, Madani Seyed M. Participation of DFIG based wind turbines in improving short term frequency regulation. Electrical Energy (ICEE); 2010:874e9. 2010 18th Iranian Conference on Digital Object Identifier.

[12] Courtecuisse V, Robyns B, Plumel S, Francois B, Deuse J. "Capacity of a variable speed turbine to participate in primary frequency control", Sixth international workshop on large-scale integration of wind power and transmission networks for offshore wind farms, Delft, October 26e27; 2006.

[13] Morren J, de Haan SWH, Ferreira JA. "Primary power/frequency control with wind turbine and fuel cells", IEEE PES General Meeting 2006, Montreal, Canada; June 2006. 